\title{
THM behaviour of engineered and natural clay barriers
}

\author{
Frédéric Collin **** - Robert Charlier*
}

\author{
* Université de Liège \\ Institut de Génie Civil et de Mécanique \\ Chemin des Chevreuils 1, 4000 Liège \\ Sart Tilman, Belgique \\ Robert.Charlier@ulg.ac.be \\ **Chargé de Recherches, Fonds National Belge de la Recherche Scientifique
}

\begin{abstract}
RÉSUMÉ. Cet article traite de deux problèmes en relation avec l'enfouissement de déchets nucléaires dans des couches géologiques profondes. D'une part, une expérience d'hydratation et de chauffage sur une argile gonflante a été conduite à petite échelle au laboratoire. Sa modélisation thermo-hydro-mécanique est proposée et discutée. D’autre part, l'extension de la zone endommagée lors du creusement d'une galerie est discutée sur base d'une modélisation hydromécanique avec une mise en évidence de la localisation des déformations en bandes de cisaillement, amorce de fractures.

ABSTRACT. This paper is concerned with two problems related to deep underground storage of nuclear waste. On one hand, a small-scale laboratory experiment has allowed to heat and wet a confined swelling clay. A thermo-hydro-mechanical modelling is proposed and discussed. On the other hand, the extent of the damaged zone produced during tunnelling in clay is discussed based on an hydromechanical modelling showing evidences of strain localisation, i.e. a fracture initiation.

MOTS-CLÉS : barrière argileuse, localisation des déformations, couplages multi-physiques, THM, hydromécanique, enfouissement de déchets.

KEYWORDS: clay barriers, strain localisation, multi-physics coupling, THM, hydromechanics, underground storage.
\end{abstract}

REGC - 9/2005. Multiphysics Geomechanics, pages 797 to 808 


\section{Introduction}

One solution nowadays proposed for long term nuclear waste is the realization of waste repositories in deep geological low permeability layers: the Boom Clay formation in Belgium, clay-stone formation in France and granite and claystone formations in Switzerland for example. In order to develop and to assess this approach, Underground Research Laboratories (URL) have been constructed in several countries in Europe (France, Switzerland, Belgium, ...). Different experiments can be achieved: on one hand, at the gallery scale, in-situ measurement are made in thermo-hydro-mechanical (THM) conditions close to those that will be created when the nuclear waste will be deposited. On the other hand, it is also interesting to achieve small-scale experiment in order to test (at lower cost) different set-up of engineered barriers. These kind of tests on the filling material (usually clay material) reproduce the conditions in the gallery: resaturation by the host formation, heat production due to waste activity and confinement of engineered barrier.

Modelling such kind of experiment requires complex constitutive laws (See [LAL05] and [GEN05] in the same book) in order to tackle the different coupled phenomena and needs also advanced experimentations in order to determine the parameters of the constitutive models. In the second section, a small-scale heating and hydration test is presented and a THM modelling is proposed.

Another aspect of this problem is the necessity to ensure that gallery excavation does not damage the host formation. Indeed if some fracturation processes appear, they will constitute preferential paths for pollutant migration like radionuclide. The tunnelling method should then minimize the damaged zone (EDZ) around the excavation. In the existing URL, the mechanical behaviour of the host formation is usually brittle and the constitutive laws usually used to reproduce their behaviour are damaged models or strain-softening models. Such kind of models allows to reproduce the progressive decrease of material strength during testing; consequently, they predict also strain localisation, which is observed in-situ ([MER 04]). In the third section, it is proposed to model the excavation process with a very simple strain-softening constitutive law in order to exhibit the main phenomena appearing during tunnelling.

\section{Modelling of the THM behaviour of unsaturated clay}

In the following, a small-scale heating and hydration test is first presented and a modelling is proposed. This latter one was a part of a benchmark exercise in the framework of CATSIUS CLAY European project ([ALO 99]): experimental results of an heating and hydration test on a clay material were known ([VIL 94], [VOL 96]). The different partners were asked to model the experiment, being free to chose the mechanical constitutive law. Series of tests on the material ([VIL 94], [PIN 97]) allow to determine the parameters. 


\subsection{Experiment set-up}

The clay material used for the experiment is the S2 bentonite, which is a montmorillonite coming from Almeria in Spain. This clay was axially compacted at a dry density of $1.66 \mathrm{~g} / \mathrm{cm}^{3}\left(S_{r w}=49 \%\right.$ and $\left.w=11.8 \%\right)$ and was inserted in a cell, which dimension (in $\mathrm{cm}$ ) are given in the Figure 1.

The total duration of the experiment is 2401.6 hours; clay sample is saturated and heated. Different temperature and water content measurement are available during the test.

- The heater is a vertical cylinder inserted in the upper part of the cell (Figure 1). It is a resistance electronically regulated by an ON/OFF temperature controller with a thermocouple sensor. A power of $40 \mathrm{~W}$ is supplied up to a temperature of $100^{\circ} \mathrm{C}$ and turned off still the temperature decreases below $97^{\circ} \mathrm{C}$. The cell containing the sample is in direct contact with ambient laboratory atmosphere, which is assumed to be at $25^{\circ} \mathrm{C}$.

- Hydration of the bottom of the sample is realized through a porous stone and the injection pressure equals 1.1 MPa.

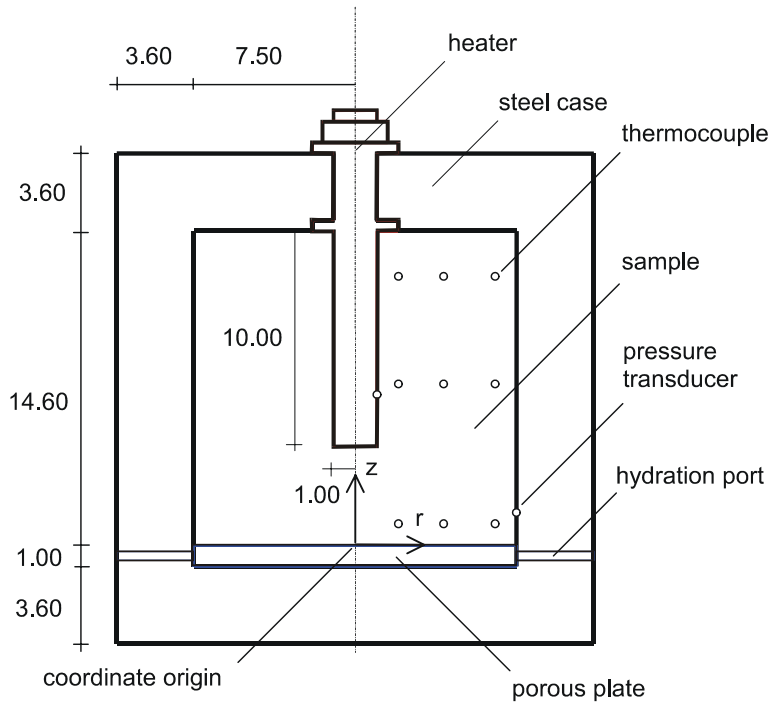

Figure 1. Experiment set-up

- During experiment, water volume intake is monitored as well as the total pressure at the bottom of the sample. Moreover, several thermocouples allow to know the temperature evolution within the 
sample all along the test. After 2401.6 hours, the clay sample is extracted from the cell and cut into slices, which allow to know the final water content distribution.

The aim of the modelling is to be able to reproduce the measurements realized during the experiment. It should be noticed that the information on the mechanical behaviour comes only from one pressure transducer. Thus sound conclusions on the mechanical aspects will not be drawn here. A contrario measurements of temperature and water content allow to have a better comprehension of hydric exchanges during experiment.

\subsection{Modelling predictions}

The constitutive law used for the mechanical behaviour of the S2-Bentonite is the BBM model ([ALO 90]), which is written in terms of net stress and suction. A multiphasic model is used to reproduce the water, air and thermal flows that appear in an unsaturated media. Water vapour flows are also taken into account (following Phillip and De Vries expression [PHI 57]) and are very important in such low permeability medium.

The determination of the model's parameters is a crucial task to get a proper modelling of the problem. Many advanced experiments are needed for the complex constitutive models we used but it remains always some parameters that the engineers have to estimate. A detailed description of the parameters determination and the numerical implementation could be found in [LI 00] and [COL 02].

In the following computations, the fully coupled finite elements have five degrees of freedom: geometrical coordinates, water pressure, gas pressure and temperature. They are used to mesh the steel case, the porous stone and the sample. Some additional boundary finite elements are needed to model the action of the heater and the thermal exchanges between the steel case and the ambient air.

\subsubsection{Initial and boundary conditions}

The sample is initially at ambient temperature $\left(T_{0}=25^{\circ} \mathrm{C}\right)$ in the steel case. Knowing the saturation of the sample at the beginning of the experiment $\left(S_{r w}=\right.$ $49 \%$ ) and assuming an atmospheric gas pressure, the initial water pressure is given by the corresponding suction and equals -78,53 MPa. The clay material is inserted in the cell without compaction and is thus initially stress free.

Injection of water is realized trough the porous stone at a pressure of 1.1 MPa. For the modelling gas pressure will be assumed constant and equal to $100 \mathrm{kPa}$. This supposes that air can flow out the cell without strong overpressure. For TH modelling, the influence of air pressure variation was studied [COL 02] and it was shown that this implies a lower water saturation degree near the heater. For the thermal problem, a $40 \mathrm{~W}$ heat flow is applied at the sample surface in contact with 
the heater and this flow is controlled in order to reach a maximum temperature of $100^{\circ} \mathrm{C}$. Moreover, thermal exchanges appear between the external face of the cell and the ambient air, due to convective fluxes. The exchange coefficient was chosen to a value of $6.5 \mathrm{~W} / \mathrm{m}^{2}$ thanks to a back analysis of the temperature field.

The steel case and the porous stone are assumed to be rigid and a perfect sliding contact condition is considered between the sample and the confinement (the cell, the porous stone and the heater).

\subsubsection{Numerical Results}

In the modelling presented here, all the physical phenomena are coupled. Therefore it is interesting to study the different problems separately to understand what appends during the experiment. Considering first the thermal problem only, the exchange coefficient is calibrated by comparison with experiment measurements. Further (coupled) computations showed that temperature field is only slightly influenced by water flow and strains. Indeed, the thermal problem is essentially conductive. Figure 2-a presents a comparison between experiments and numerical responses (for coupled T-H-M modelling), at the bottom, the middle and the top of the sample. Predictions are very closed to the measurements except at the middle near the heater where the model overestimates the temperature. Of course, these results show that temperature is higher near the heater (about $75^{\circ} \mathrm{C}$ in $1 \mathrm{~cm}$ from the heater). Material is colder far from the hot spot: temperature is then directly related by the ambient air temperature. It is also important to notice that temperature field does not vary much between 25.6 hours and the end of experiment. Indeed, thermal steady state is reached after 13 hours [VIL 94].

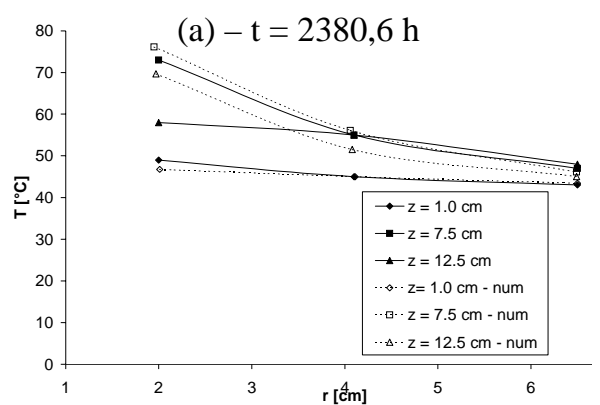$$
\text { int }
$$

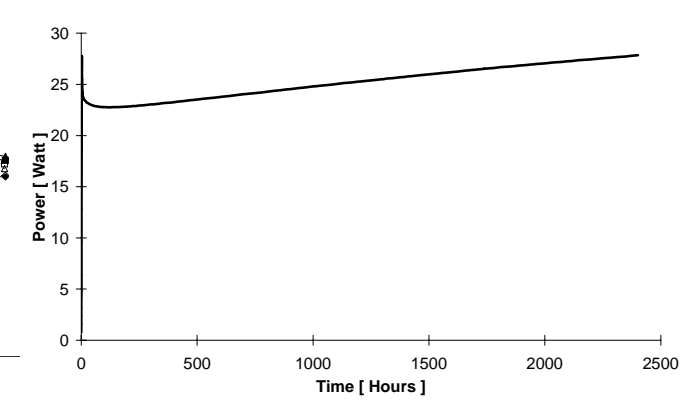

(b)

Figure 2. Temperature field in the sample

The supplied heat power is sufficient enough to reach $100^{\circ} \mathrm{C}$ at the heater. In the beginning of the experiment, the power actually supplied is equal to $27 \mathrm{~W}$. Then, it decreases to $23 \mathrm{~W}$ and finally increases during the remaining experiment time due to the progressive sample resaturation (Figure 2-b). 
During the experiment, water injection is realized at the bottom of the sample. Figure 3-a shows that the model reproduces very well the water intake curve. The curve depends mainly on the bentonite permeability. However, it is not much influenced by the thermal field. Experiment shows clearly a resaturation of the sample, from its bottom and a desiccation of the clay near the heater due to the increase of temperature and the water vapour transfer (Figure 3-b). Thus, in order to reproduce the desaturation, it is necessary to include in the model water vapour flow; if it is not the case, desaturation will not be very important. Related to this effect, the parameter controlling the intensity of vapour fluxes is the tortuosity. The value chosen (tortuosity $=0.15$ ) was calibrated by back analysis in order to reproduce the water content near the heater. At the end of the experiment, despite the water injection at the bottom, water content near the heater has decreased due to water evaporation. Near the bottom of the sample, clay is fully saturated and the water content is about $35 \%$.
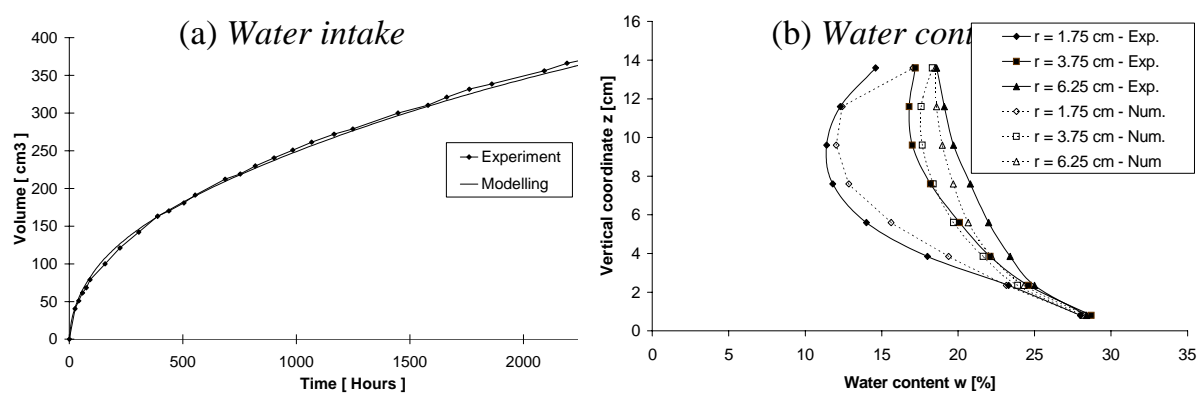

Figure 3. Hydric transfer in the sample

Due to the confinement of the sample, clay material cannot sustain large strains; thus a swelling pressure is created, and the porosity changes, what has a strong influence on the water content (figure 3-b). Indirectly, it appears that the model mechanical response is qualitatively good.

\subsection{Conclusions}

The developed model was able to predict the bentonite behaviour under thermohydro-mechanical loading. Modelled temperatures are quite equivalent to measured ones. The hot zone $\left(\mathrm{T}=100{ }^{\circ} \mathrm{C}\right)$ is located near the heater while the temperature near the casing is controlled by the convection condition with ambient air.

Water content modelled and measured are similar; a saturated zone is produced near the porous stone. In the upper part of the sample, the bentonite cannot fully saturate, because the water is vaporised near the heater and the material is dried. 
Water transfers in vapour phase are therefore crucial to be modelled in such kind of problem.

Eventually, it should be noticed that such a modelling was possible thanks to a very large experimental program on bentonite material. This allowed to determine its mechanical, hydraulic and thermal properties. The models ask for many parameters, which is consequence of the modelling complexity of highly coupled phenomena.

\section{Tunnelling in clay/claystone for nuclear waste disposal}

In the following, it is proposed to model the excavation process with a very simple strain-softening constitutive law in order to exhibit the main phenomena appearing during tunnelling : the progressive decrease of material strength during testing and the strain localisation. This coupled modelling is a benchmark exercise proposed by the GDR-Momas and organized by EDF-CEA ([CHA 05]).

\subsection{Description of the problem}

The proposed constitutive law is an elasto-plastic strain-softening model. The yield criterion is a Drucker-Prager model given by the following equation:

$$
F \equiv \sqrt{\frac{3}{2}} I I_{\sigma^{*}}+m\left(I_{\sigma}-\frac{3 c}{\tan \phi}\right)=0
$$

where $I I_{\sigma^{*}}$ is the second deviatoric stress invariant, $I_{\sigma}$ is the first stress invariant, $\phi$ is the friction angle, parameter $m$ is a function of $\phi: m=2 \sin (\phi) /(3-\sin (\phi))$, the cohesion $c=c_{0} f\left(\gamma^{p}\right)$ is the softening variable, $c_{0}$ is the initial cohesion and $\gamma^{p}$ is the equivalent deviatoric plastic deformation.

A cylindrical unsupported cavity of $3 \mathrm{~m}$ diameter is located in an homogeneous low permeability formation. The initial state of stress and pore pressure is the following:

$$
\begin{aligned}
& \sigma_{x x}^{\prime}=\sigma_{z z}^{\prime}=-7.74 M P a \\
& \sigma_{y y}^{\prime}=-11.64 M P a \\
& p_{w}=4.7 M P a
\end{aligned}
$$

The excavation process is modelled by decreasing both radial total stress and the pore pressure at the cavity nodes: 


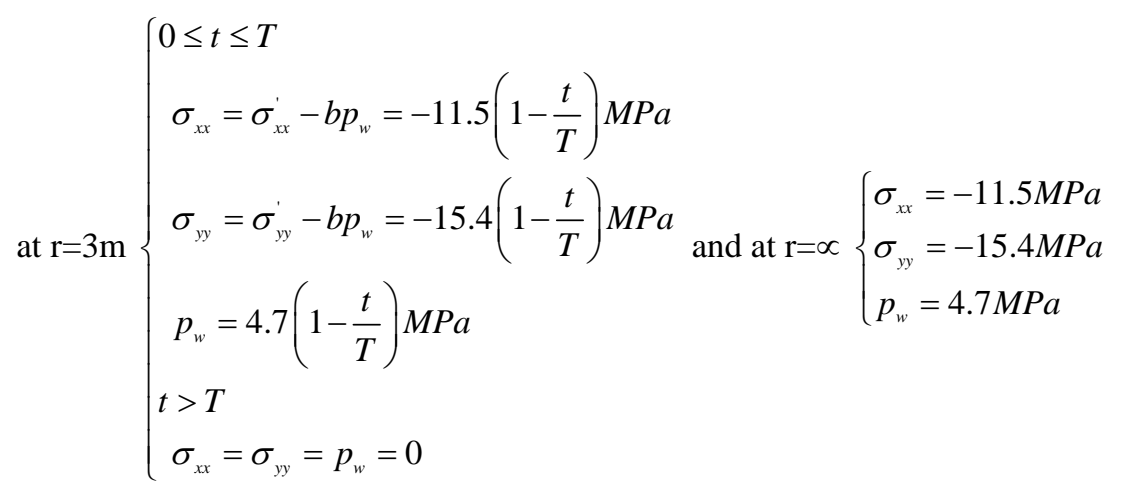

The excavation duration $T$ is equal to 1.5 Ms (about 17 days) and the final modelling time is $300 \mathrm{Ms}$ (about 9.5 years).

\subsection{Model predictions}

During the excavation, the behaviour of the material becomes plastic near the tunnel and permanent strains are created. The yield criterion is first met in the direction where the orthoradial stress is the major principal stress. Dilatancy effects are evidenced on Figure 4-a, where the pore pressure becomes negative at the end of the tunnelling. Then, during the remaining modelling time, the pore pressure increases progressively. Figure 4-b shows the radial displacement curve: during the tunnelling phase, cavity convergence remains around $1,5 \mathrm{~cm}$. Most of the convergence appears later and reaches 22,6 cm. Indeed, negative pore pressure allows a additional cohesive strength; this effect is maximum after 1,5 Ms and decreases progressively still 300 Ms.

Shear band localization is also influenced by the hydro-mechanical coupling. Indeed, at the end of excavation, there is no clear localization patterning even if the Rice's criterion is verified. After that phase, pore pressure increases progressively and a patterning is gradually created. Figure 5-a presents a map of equivalent strains, where the different shear bands appears clearly. The Vilotte's indicator is shown in Figure 5-b; this indicator evidences the strain activity of the shear band. One can see here that only the external shear band is active at the end of the simulation and that a chip is finally created. It is clear however that these results are mesh dependent and enhanced models are necessary for an objective postlocalization modelling (See [ZER 01] for an example of excavation and [ZHA 04], [CHA 04] for coupled enhanced models). 


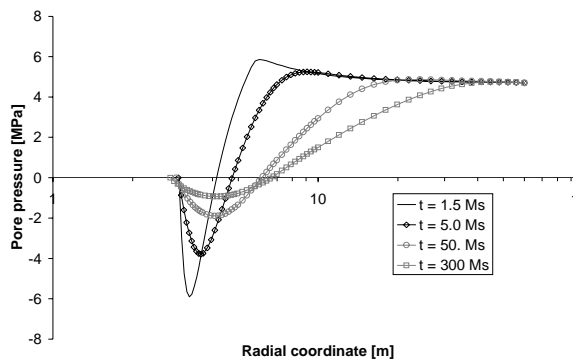

(a)

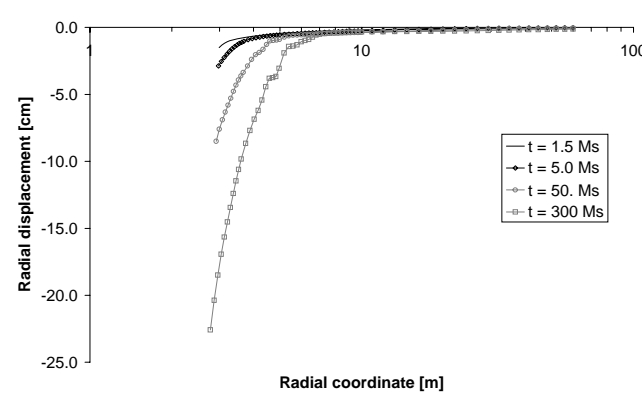

(b)

Figure 4. Pore pressure and displacement curve during coupled excavation

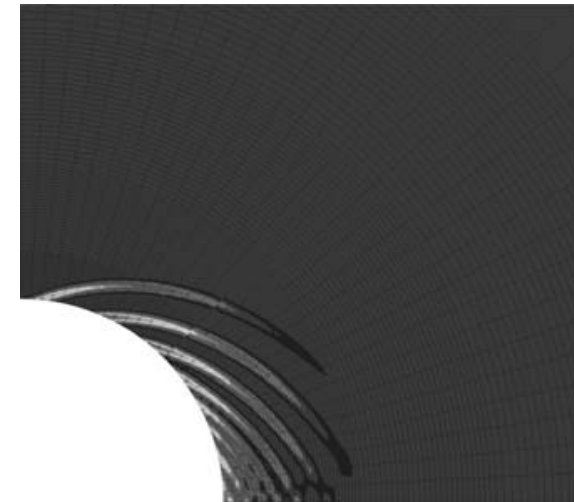

(a)

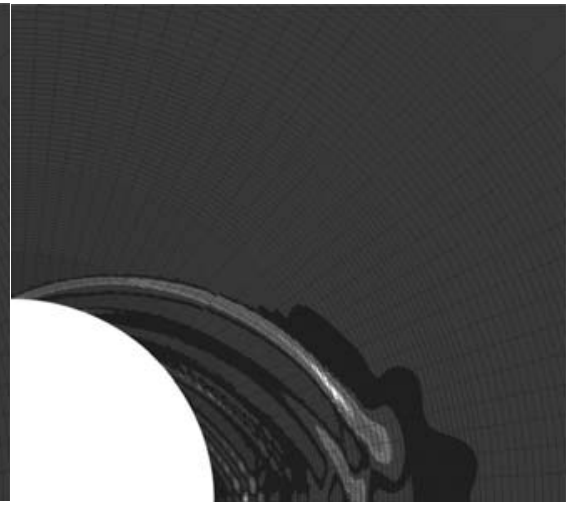

(b)

Figure 5. Equivalent strain and Vilotte's indicator for active shear band $(t=$ 300Ms)

\subsection{Influence of hydric boundary condition}

In the previous section, the boundary condition for the flow problem is the following: a decrease of the pore pressure from its initial value till the atmospheric pressure (Defined as Case A). Due to the hydro-mechanical coupling (dilatancy effect), this implies an injection of water into the formation (See Figure 4-a). A more realistic condition is a dripping boundary condition: a water flow can be 
created only if the pore pressure in the formation is greater than the atmospheric pressure (Unilateral flow condition). This case will be referred as case B in the following. For long-term predictions, one can assumed an equilibrium between the pore pressure at the tunnel and the relative humidity of the cavity atmosphere. Indeed, this relative humidity can be controlled in waste disposal. A third case (Case C) is then considered, where a negative pressure of $-5 \mathrm{MPa}$ is imposed as boundary condition.

Figure 6 shows the resulting pore pressure distribution for the two latter cases. In Case $\mathrm{B}$, the pore pressure becomes negative near the cavity at the end of the excavation. Then pore pressure increases progressively. In case $C$, the results is similar at the end of the excavation. However, after this first phase, the pore pressure remains negative as it is imposed by the boundary condition and the suction diffuses in the formation.

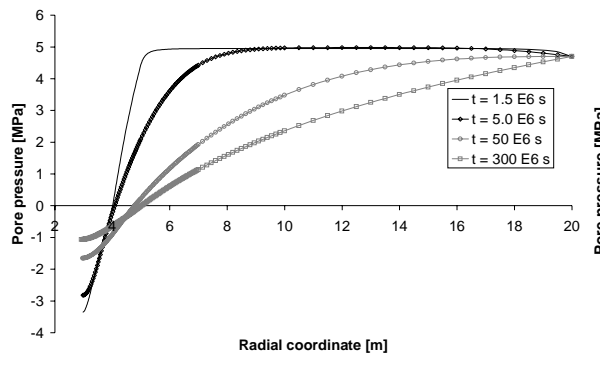

(a) Case B

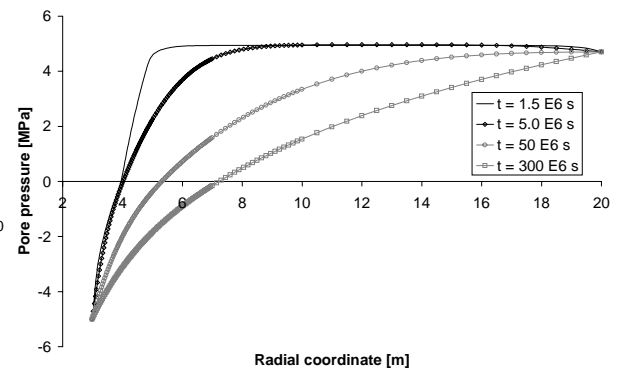

(b) Case C

Figure 6. Pore pressure distribution in case B and case $C$

These pore pressure distributions have a direct influence on the convergence predicted. Table 1 presents the results for the three cases. At the end of the excavation, the convergences are more ore less the same. But for the long-term response, the predicted displacements are rather different. Indeed in case $C$, the remaining suction near the tunnel ensures an additional strength and limits the material deformations. Moreover, the boundary condition inhibits totally the creation of shear bands pattern. The case $\mathrm{C}$ condition is then conservative in comparison with the two other ones.

\begin{tabular}{c||c|c|c}
\hline & Case A & Case B & Case C \\
\hline \hline $\mathrm{t}=1,5 \mathrm{Ms}$ & $1,5 \mathrm{~cm}$ & $1,26 \mathrm{~cm}$ & $1,42 \mathrm{~cm}$ \\
$\mathrm{t}=300 \mathrm{Ms}$ & $22,6 \mathrm{~cm}$ & $12,8 \mathrm{~cm}$ & $1,44 \mathrm{~cm}$ \\
\hline
\end{tabular}

Table 1: Cavity convergence for Cases A, B and C. 


\subsection{Conclusions}

Tunnelling in clay formations may induce strain localisation and fracture, as recently observed in Mol URL. An hydromechanical modelling with a strain softening constitutive model allows to reproduce such phenomena. The results are strongly dependent on the hydraulic boundary condition at the tunnel face, which has to be better analysed.

\section{Conclusions}

Deep underground storage of (high level and long life) nuclear waste induces severe conditions on the host rock (especially of clay/claystone) and on the engineered barrier, which is generally made of swelling clay. The long-term integrity of the permeability barriers has to be proved. The good understanding of such disposal needs high-level numerical models, including different aspects: thermal and partial saturation hydraulics effects, suction-mechanics interaction, strain localisation and fracture prediction. Highly coupled non-linear finite element codes are today necessary to tackle such challenge.

\section{Acknowledgments}

The authors are grateful to FNRS and UE (under RTN-DIGA project) for the help and grant they received.

\section{References}

[ALO 90] Alonso E. E., Gens A., Josa A., A constitutive model for partially saturated soils, Géotechnique 40(3), pp 405-430, 1990.

[ALO 99] Alonso E., Alcoverro J., CATSIUS CLAY PROJECT, Calculation and Testing of Behaviour of Unsaturated Clay as Barrier in Radioactive Waste Repositories, Stage 2 : Validation exercises at laboratory scale, Publication Tecnica Num. 11/99, 1999, ENRESA.

[CHA 04] Chambon R., Collin F., Hydro mechanical numerical modelling of geotechnical problems using local second gradient models, Modelling of Cohesive Frictional Materials Vermeer Ehlers Hermann Ramm eds. AA Balkema, 2004, pp. 209-221

[CHA 05] Chavant C., Fernandes R., Evaluating the reliability of hydro-mechanical simulation : a benchmark of numerical techniques carried out by Research Group of MoMas, $2^{\text {nd }}$ International Meeting Clays in Natural \& Engineered Barriers for Radioactive Waste Confinement, Tours, 14-18 March 2005, pp 249-250. 
[COL 02] Collin F., Li X.L., Radu J.P., Charlier R., Thermo-hydro-mechanical coupling in clay barriers, Engineering Geology, 64, 2002, pp. 179-193.

[GEN 05] Gens A., Guimarães L., Olivella S., THMC coupling in partially saturated geomaterials. Revue Européenne de Génie Civil, 2005.

[LAL 05] Laloui L., Cekerevac C., François B.Constitutive modelling of the thermo-plastic behaviour of soils. Revue Européenne de Génie Civil, 2005.

[LI 00] Li X.L., Comportement hydromécanique des sols fins : de l'état saturé à l'état nonsaturé, PhD Thesis, University of Liège, 2000.

[MER 04] Mertens J., Bastiaens W., Dehandschutter B., Characterisation of induced discontinuities in the Boom Clay around the underground excavations (URF, Mol, Belgium), Applied Clay Science 26, pp 413- 428, 2004.

[PHI 57] Philip J.R., De Vries D.A., Moisture movement in porous materials under temperature gradients, EOS Trans. AGU, 38(2), pp 222-232, 1957.

[PIN 97] Pintado X., Lloret A. \& al., TMH Laboratory tests in FEBEX phase 3, UPC Report 70-UPC-L-3-01, Barcelona, 37 pp, 1997.

[VIL 94] Villar M.V. \& al., Modelling and validation of the thermal-hydraulic-mechanical and geochemical behaviour of the clay barrier, Final report 1991-1994 CEC Contract FI2W-CT91-0102 (DOEO), 1994, CIEMAT Madrid.

[VOL 96] Volckaert G., Bernier F., Alonso E., Gens A., Samper J., Villar M., Martin-Martin P.L., Cuevas J., Campos R., Thomas H., Imbert C., Zingarelli V., Thermal-hydraulicmechanical and geochemical behaviour of the clay barrier in radioactive waste repositories (Model development and validation), Final report Contract Nos FI2W/CT90/0033 and FI2W/CT91/0102, 1996, European Commission, Nuclear science and technology.

[ZER 01] Zervos A., Papanastasiou P., Vardoulakis I., Modelling of localisation and scaleeffect in thick-walled cylinders with gradient elastoplasticity, Int. J. Solids and Struct. 38, 2001, pp. 5081-5095.

[ZHA 04] Zhang C, Schrefler B.A., Particular aspects of internal length scales in strain localization analysis of multiphase porous materials. Computer Methods in Applied Mechanics and Engineering, 193, 2004, pp. 2867-2884. 